\title{
Epidemiological Analysis of Peste des Petits Ruminants (PPR) Outbreaks in Pakistan
}

\author{
Aamer Bin Zahur1', Aman Ullah', Hamid Irshad1*, Asma Latif1, Riasat Wasee Ullah1, \\ Muhammad Jahangir'1, Muhammad Afzal' ${ }^{2}$, Shahid Ali Khan², Sarosh Majid Salaria ${ }^{3}$ \\ ${ }^{1}$ Animal Health Research Laboratories, Animal Sciences Institute, National Agricultural Research Centre, Park \\ Road, Chak Shahzad, Islamabad, Pakistan \\ ${ }^{2}$ FAO-UN Pakistan (GCP/PAK/127/USA), NARC, Park Road, Islamabad, Pakistan \\ ${ }^{3}$ Azad Jammu and Kashmir Medical College, Muzaffarabad, Azad Kashmir \\ Email: ${ }^{*}$ hamidirshad@hotmail.com
}

Received July 2014

\section{Abstract}

The current study reports the outbreaks of Peste des Petits Ruminants (PPR) in the small ruminant population of Pakistan. The objectives were to understand the clinical picture of disease under field conditions, estimate the basic epidemiological parameters for the local population of small ruminants and to determine the spatial and temporal distribution of PPR during 2005 to 2007 in Pakistan. A total of 62 outbreaks were investigated among sheep and goat flocks in the five provinces of Pakistan and Azad Jammu \& Kashmir (AJK). The PPR virus activity in these outbreaks was demonstrated by clinical picture and presence of PPR virus specific antibodies by employing cELISA. The combined estimates of mean cumulative morbidity and mortality for sheep and goats were estimated $65.37 \%$ and $26.51 \%$ respectively with a case fatality of $40.40 \%$. The species specific mean cumulative morbidity, mortality and case fatality for goats were $68.80 \%$, $29.45 \%$ and $42.75 \%$ respectively, while these estimates for sheep were $48.77 \%, 14.98 \%$ and of $26.16 \%$ respectively. These estimates for goats were significantly higher $(P<0.001$ to $P=0.001)$ than those for sheep. It was concluded that PPR is wide spread throughout the country and epidemiological picture suggest that disease has established as an endemic infection in the country.

\section{Keywords}

PPR, Sheep, Goat, Cumulative Morbidity, Cumulative Mortality, Case Fatality

\section{Introduction}

Peste des Petits Ruminants (PPR) is an "acute, highly contagious and frequently fatal viral disease of sheep, goats and wild small ruminants" [1]. It is characterized by fever, muco-purulent ocular and nasal discharges, necrotizing and erosive stomatitis, severe enteritis and pneumonia leading to death [2].

PPR is a trans-boundary animal disease (TAD) of significant economic importance [3], ranking among the top

\footnotetext{
${ }^{*}$ Corresponding author.
}

How to cite this paper: Zahur, A.B., Ullah, A., Irshad, H., Latif, A., Ullah, R.W., Jahangir, M., Afzal, M., Khan, S.A. and Salaria, S.M. (2014) Epidemiological Analysis of Peste des Petits Ruminants (PPR) Outbreaks in Pakistan. Journal of Biosciences and Medicines, 2, 18-26. http://dx.doi.org/10.4236/jbm.2014.26004 
ten diseases affecting small ruminants [4]. It has been described as the most important single cause of morbidity and mortality in small ruminant in Nigeria [5]. There are over 80 million goats and sheep in Pakistan.

The causal agent, PPR virus (PPRV), is an enveloped ribonucleic acid virus of the genus Morbillivirus of family Paramyxoviridae [6]. The disease was first reported in Cote d'Ivoire in 1942 [7]. At present, it is endemic across the Sub-Saharan Africa, Morocco, Arabian Peninsula, Middle East, Turkey, Iran, Iraq, Pakistan, India, Bangladesh, Nepal, Tajikistan and Kazakhstan, Tibet and China [8]-[12]. The disease was first recorded in Pakistan during 1991 [13]. However, there are limited reports, which have attempted to document the prevalence and demonstrated continuing activity of PPRV in the country [14]-[16].

This study was therefore designed to gain an insight into the epidemiology of PPR. The outbreaks of PPR were investigated countrywide to understand the clinical picture of disease, estimate the basic epidemiological parameters for the local population of small ruminants and determine the spatial and temporal distribution of these outbreaks during 2005 to 2007 in Pakistan.

\section{Materials and Methods}

\subsection{Outbreaks Investigation}

During the rinderpest eradication campaign in Pakistan (2002-2007), trans-boundary animal disease (TAD) officers were officially appointed to monitor the rinderpest surveillance activities in each province/region of country. These TAD officers served as resource persons for this study. The suspected outbreaks of PPR reported by these resource persons in their respective regions were investigated during 2005-2007. After receiving a report of an outbreak, the affected flocks/farm was visited to collect samples and field data.

\subsection{Epidemiological Observations}

Structured epidemiological investigations were carried out in each flock to determine the most probable source of PPRV transmission. These included information like previous history of disease at the farm, vaccination status of the flock, flock size and type, number of animals affected, number of dead animals and history of a PPR outbreak in the nearby farm/area.

\subsection{Data Analysis}

The epidemiological parameters including cumulative morbidity, mortality and case fatality rates were calculated using following formulae [17];

$$
\begin{gathered}
\text { Cumulative Morbidity }=\left(\frac{\text { Number of animals affected }}{\text { Total number of animals initially at risk }}\right) \times 100 \\
\text { Cumulative Morbidity }=\left(\frac{\text { Number of animals died }}{\text { Number of animals initially at risk }}\right) \times 100 \\
\text { Case Fatality }=\left(\frac{\text { Number of animals died }}{\text { Number of animals affected }}\right) \times 100
\end{gathered}
$$

These parameters were calculated for each flock. The mean cumulative morbidity was taken as the mean of cumulative morbidities of all flocks. Similar approach was followed for calculating the mean cumulative mortality and case fatality of PPR.

The 95\% confidence intervals (95\% CI) for these parameters were calculated using the formula [18];

$$
95 \% \mathrm{CI}=x \pm[1.96 \times \text { s.e }]
$$

Where $x$ is the mean of the parameter and s.e. is the standard error of mean calculated as:

$$
\text { s.e }=s / \sqrt{n}
$$

and $n$ is the sample size.

The difference in the means of these parameters for goats and sheep was estimated by t-test for unpaired samples. 


\subsection{Mapping of PPR Outbreaks}

The geographical coordinates i.e. latitude and longitude were recorded using a geographical positioning system (GPS) tracker. PPR outbreak locations were mapped along with small ruminants population in all the districts of Pakistan. Arc view 3.2 was used to develop the disease maps.

\subsection{Clinical Examination}

Clinical examination of the diseased animals was carried out in each affected flock. The rectal temperature of affected animals was recorded. The affected or "morbid" animals were defined as those showing anorexia, depression and an elevated body temperature over $105^{\circ} \mathrm{F}$. Animals were examined for the presence of clinical signs of PPR i.e. fever, discharges (ocular and nasal), erosive/necrotic mouth lesions, bronchopneumonia and diarrhea.

\subsection{Sample Collection}

A total of 630 serum samples were collected from clinically suspected or morbid goats and sheep in these flocks. The blood was collected from the affected flocks by jugular vein puncture. It was left to clot in cold boxes with ice packs. The sera was harvested into sterile tubes and was transferred to laboratory in cool box with ice packs. The serum samples were centrifuged to remove the remaining blood cells in the laboratory and were stored at $-20^{\circ} \mathrm{C}$ in sterile $2 \mathrm{ml}$ cryo-vials till further analysis.

\section{Sample Analysis}

\subsection{Detection of PPRV Specific Antibodies in "Morbid" Goats and Sheep}

The serum samples $(n=630)$ were examined for the presence of PPRV specific antibodies. The competitive ELISA (cELISA) kit, manufactured jointly by Biological Diagnostic supplies Limited (BDSL), Flow Laboratories and Institute for Animal Health, Pirbright, Surrey, United Kingdom was used to analyze samples. The assay was conducted as described by Anderson and McKay [19].

The ELISA micro plate was read using an immuno-skan reader with an inference filter of $492 \mathrm{~nm}$. ELISA Data Interchange (EDI) software [20], was used to automate the reading and calculation of percentage of inhibition (PI) values. Sera samples showing more than 50 percent inhibition (PI) of mean OD values were taken as positive for PPR antibodies provided other controls fell within the range.

\subsection{Detection of PPRV Antigens in "Morbid" Goats and Sheep}

The presence of PPRV antigens as evidence of PPRV infection in the tissue samples $(n=397)$ collected at necropsy was examined. The immune capture ELISA (IcELISA) kit produced jointly by Biological Diagnostic supplies Limited (BDSL) with the collaboration of Flow Laboratories and CIRAD, EMVT, France was used for this purpose. The standardized reagents, bench protocol and manual were supplied along with the kit. Each of the tissue sample was processed to make a slurry and was tested by IcELISA using the standard protocol [21]. The optical densities of the samples were measured at $492 \mathrm{~nm}$ with an automated ELISA reader Immunoscan plus (Flow laboratories) using ELISA Data Interchange (EDI) software used to automate the reading and calculation of percent positivity (PP) values [20]. The samples with positive percentage (PP) value greater than $18 \%$ were considered positive.

\section{Results}

\subsection{Outbreaks}

A total of 62 outbreaks were investigated in different parts of the country during 2005-2007 (Table 1). The locations of PPR outbreaks recorded during the study are presented in Figure $\mathbf{1}$ and temporal distribution of these outbreaks is shown in Figure 2.

\subsection{Clinical Observations}

A total of 8033 animals were examined (goats $=5666$ and sheep $=2367$ ). The number of affected animals was 
Table 1. Region-wise breakup of reported PPR outbreaks investigated during 2005-2007.

\begin{tabular}{ccc}
\hline Region & Frequency & Percent \\
\hline Gilgat Baltistan & 3 & 4.84 \\
AJK & 7 & 11.29 \\
Punjab & 18 & 29.04 \\
Baluchistan & 7 & 11.29 \\
Sindh & 15 & 24.19 \\
KPK $^{* *}$ & 12 & 19.35 \\
Total & $\mathbf{6 2}$ & $\mathbf{1 0 0}$ \\
\hline
\end{tabular}

AJK: Azad Jammu and Kashmir; ${ }^{* *}$ KPK = Khyber Pukhtunkhwa.

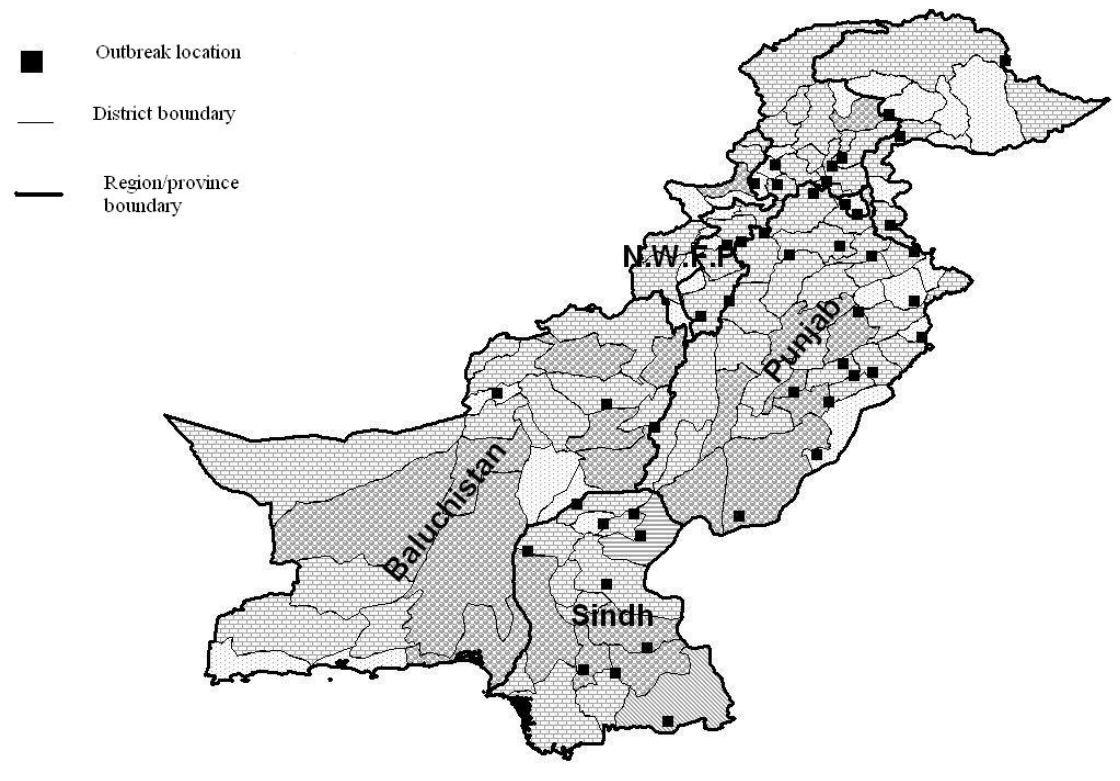

Figure 1. Map depicting the locations of outbreak sites along with small ruminant population in all the districts of country. Squares show the location of infected flocks. Livestock density is given in the background (Livestock census 2006). Arcview ${ }^{\circledR} 3.2$ was used to develop this map.

4658 (goats $=3438$, sheep $=1220)$. The clinical examination of the affected animals revealed high fever $\left(39^{\circ} \mathrm{C}-\right.$ $41.6^{\circ} \mathrm{C}$ ), conjunctivitis, catarrhal ocular and nasal discharges along with anorexia, depression, swollen lips, cough and diarrhea. Most animals exhibited severe dehydration and soiling of hindquarters due to diarrhea. In the animals examined earlier during the course of disease, a red raw area, erosion and/or necrosis of lower gums just beneath the insertion of incisors was observed. Such lesions were also observed on the inner side of the lips, cheek papillae, dorsal surface of the tongue and hard palate.

\subsection{Epidemiological Observations}

A total of 62 flocks with an active PPR outbreak were investigated. All the sampled animals belonged to open sedentary farms in rural areas except one nomadic flock. Total livestock population of these flocks was 8033 animals. The flock size varied widely and ranged from 8 to 355 animals with an average flock size of 129.56 


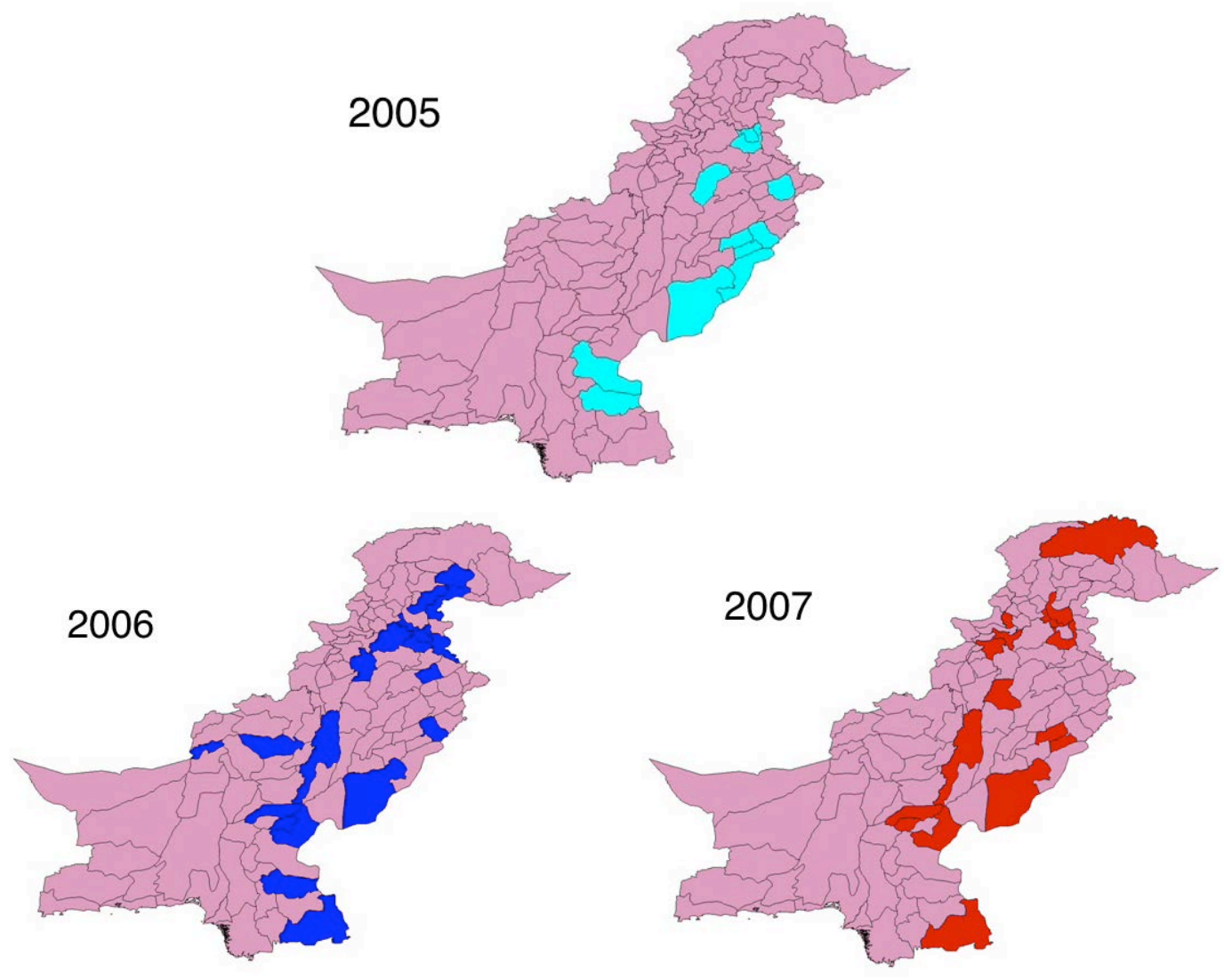

Figure 2. Temporal Distribution of PPR outbreaks in Pakistan (2005-2007). The violet, blue or red areas show the districts where PPR was reported during the mentioned year. Arcview ${ }^{\circledR} 3.2$ was used to develop this map.

and a median size of 80 animals. Of 8033 animals, 5666 (70.53\%) were goats. The number of goats in each flock ranged from 02 to 1000 with 96.04 animals being the mean size and 60 animals as median size of flocks. Of 2367 sheep in these 62 flocks, the number ranged from 10 to 270 with a mean size of 38.80 and a median size of 25 animals.

All the flocks followed a communal grazing pattern in open pastures near the villages and/or with occasional supplementation with stall-feeding. All the flocks, which experienced PPR, either had a recent history of a new animal introduced/purchased/returned from a livestock market (20 flocks) and communal grazing with local (24 flocks) or nomadic animals (18 flocks).

\subsection{Epidemiological Parameter Estimates}

Of the 8033 animals in 62 flocks, 4657 were found morbid. The distribution of morbid and dead animals is shown in Figure 3. The cumulative morbidity, mortality and case fatality varied widely among different flocks and in both species. The combined estimates of mean cumulative morbidity and mortality for sheep and goats were estimated $65.37 \%$ and $26.51 \%$ respectively with a case fatality of $40.40 \%$ (Table 2 ). The species specific mean cumulative morbidity, mortality and case fatality for goats were $68.80 \%, 29.45 \%$ and $42.75 \%$ respectively, while these figures were on lower side for sheep with estimated values of $48.77 \%, 14.98 \%$ and of $26.16 \%$ respectively. These estimates for goats were significantly higher $(\mathrm{p}<0.001$ to $\mathrm{p}=0.001)$ than those for sheep (Table 2).

\subsection{Detection of PPRV Specific Antibodies}

The antibodies against PPR virus were detected in the serum samples from 62 outbreaks. Of 630 serum samples, 386 were found positive for antibodies against PPR, with a positive percentage of 61.27\% (Table 3). 


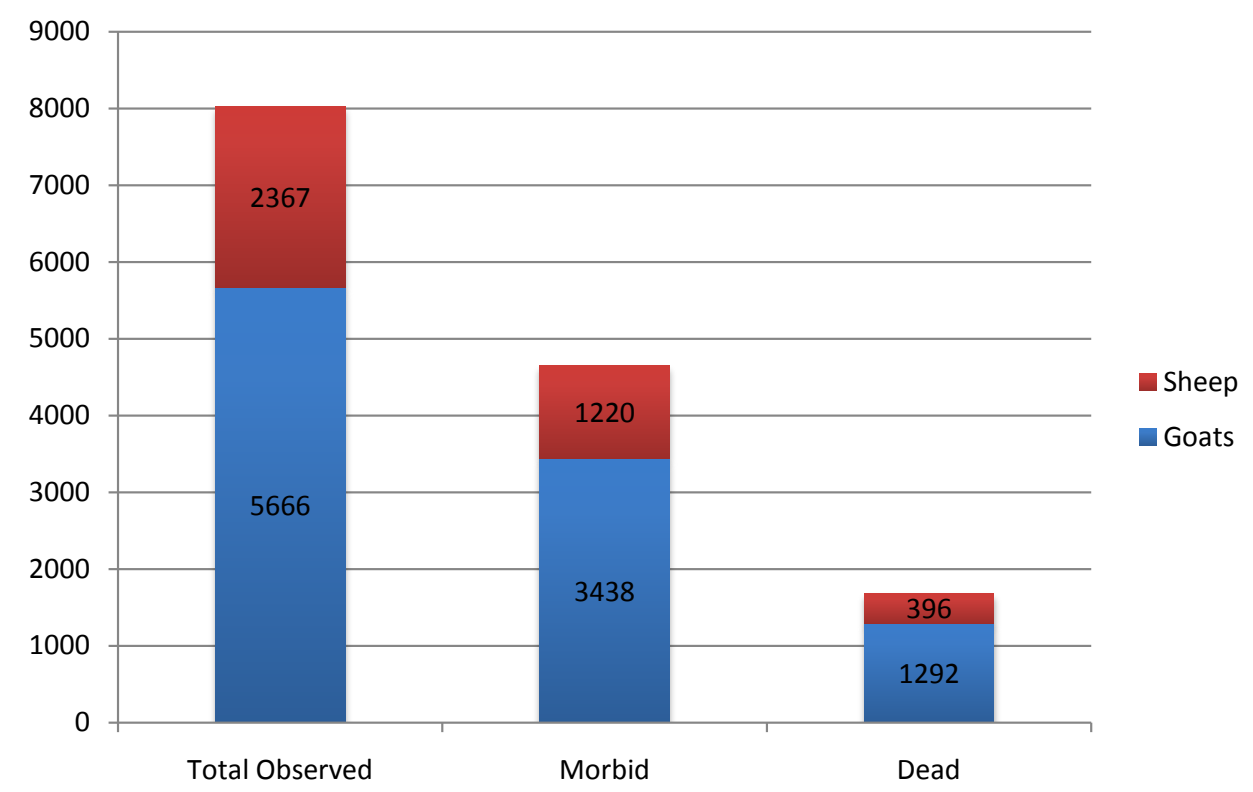

Figure 3. Bar graph showing the distribution of total, affected or dead animals in the outbreaks.

Table 2. Estimates of various epidemiological parameters for PPR from outbreaks in Pakistan (2005-2007).

\begin{tabular}{|c|c|c|c|c|c|c|}
\hline Parameter & Combined (95\% CI) & Species & Flocks & $\begin{array}{c}\text { Mean } \\
(95 \% \text { CI })\end{array}$ & $\begin{array}{c}\text { Difference in mean } \\
(95 \% \mathrm{CI})\end{array}$ & $\mathrm{p}$ \\
\hline $\begin{array}{l}\text { Mean Cumulative } \\
\text { Morbidity (\%) }\end{array}$ & $\begin{array}{c}65.37 \\
(58.02-72.72)\end{array}$ & Goats & 40 & $\begin{array}{c}68.80 \\
(60.68-76.92) \\
48.77 \\
(38.86-58.68)\end{array}$ & $\begin{array}{c}20.03 \\
(7.39-32.67)\end{array}$ & 0.001 \\
\hline $\begin{array}{l}\text { Mean Cumulative } \\
\text { Mortality (\%) }\end{array}$ & $\begin{array}{c}26.51 \\
(21.54-31.47)\end{array}$ & Goats & 59 & $\begin{array}{c}29.45 \\
(23.34-35.56) \\
14.98 \\
(9.41-20.54)\end{array}$ & $\begin{array}{c}14.48 \\
(6.32-22.64)\end{array}$ & $<0.001$ \\
\hline $\begin{array}{l}\text { Mean Case Fatality } \\
\text { (\%) }\end{array}$ & $\begin{array}{c}40.40 \\
(34.41-45.88)\end{array}$ & Goats & 56 & $\begin{array}{c}42.75 \\
(36.01-49.49) \\
26.16 \\
(18.41-33.92)\end{array}$ & $\begin{array}{c}16.58 \\
(6.33-26.84)\end{array}$ & $<0.001$ \\
\hline
\end{tabular}

95\% CI = Lower and upper 95\% confidence intervals.

Table 3. Serum samples collected from suspected outbreaks of PPR tested by cELISA.

\begin{tabular}{cccc}
\hline Region & Samples & Positive & \%Positive \\
\hline Punjab & 401 & 264 & 65.84 \\
Sindh & 42 & 27 & 64.29 \\
KPK $^{*}$ & 46 & 16 & 34.78 \\
Baluchistan & 80 & 42 & 52.50 \\
GB \&AJK & 61 & 37 & 60.66 \\
Total & 630 & 386 & 61.27 \\
\hline
\end{tabular}

* KPK: Khyber Pukhtunkhwa; ${ }^{* *}$ AJK: Azad Jammu and Kashmir. GB = Gilgat Baltistan.

\subsection{Detection of PPRV Antigen}

The tissue samples collected during these outbreaks were found positive for PPR virus antigen using IcELISA. Out of 397 samples tested, 258 were found positive for PPR virus with a positive percentage of 64.99\% (Table 4). 
Table 4. Tissue samples collected from suspected outbreaks tested by IcELISA for PPR virus.

\begin{tabular}{cccc}
\hline Region & Samples & Positive & \% Positive \\
\hline Punjab & 166 & 116 & 69.88 \\
Sindh & 144 & 91 & 63.19 \\
KPK & 42 & 23 & 54.76 \\
Baluchistan & 15 & 9 & 60.00 \\
AJK & 17 & 11 & 64.71 \\
Northern Areas & 13 & 8 & 61.54 \\
Total & 397 & 258 & 64.99 \\
\hline
\end{tabular}

AJK: Azad Jammu and Kashmir; KPK: Khyber Pukhtunkhwa.

\section{Discussion}

The current study was undertaken to ascertain the current status of PPR in Pakistan by recording the PPR outbreaks in the country. The presence of PPRV virus in these outbreaks was demonstrated by clinical picture and the PPR virus specific antibodies were detected by employing cELISA.

Obviously, the serum antibodies take some time to develop following an infection. Therefore, results of sero diagnosis may be biased. Some animals that were positive for PPR antibodies by cELISA may have historic exposure to PPRv, long before the recent outbreak. Others may still not have developed a detectable antibody titre. However, the results of serology clearly indicate that many of the animals have developed detectable immune response. This may reflect the immunogenic potential of the circulating PPRv strains.

About $65 \%$ of the tissue samples collected during these outbreaks were positive for PPR virus antigen by IcELISA (Table 4). This clearly indicates that majority of flocks in fact had a severe attack of PPRv. Some of the morbidity or mortality may be attributed to other diseases in larger flocks or complicated cases. However, results of Ic-ELISA and cELISA indicated that morbidity and mortality is most likely due to PPR and any other causes are unlikely.

The cumulative morbidity, cumulative mortality and case fatality were estimated for both species. During these outbreaks, some flocks showed as high as $100 \%$ of morbidity, mortality or case fatality especially in goats (Table 2). This is probably due to the fact that at least some of these flocks experienced PPR outbreak for the first time. Many farmers were not aware of any such disease earlier and thus experienced heavy losses in terms of morbidity and mortality.

The combined estimates of cumulative morbidity, cumulative mortality and case fatality for goats and sheep are very high. The mortality in acute outbreak reaches $80 \%$ with the affected animal dying between 10 - 12 days [22]. Similar estimates for morbidity, mortality and case fatality have been reported $(52.11 \%, 21.14 \%$ and $40.57 \%$ respectively) at village farms and an overall mortality of $23.1 \%$ in Black Bengal goats in Bangladesh [23]. In endemic areas the mortality rates may be as low as $20 \%$ with outbreaks occurring at regular interval [24]. These similar estimates reflect endemism the fact that PPR is a regional problem and countries in South Asia may be facing a similar threat by PPR. This calls for a collaborative regional effort for the control of this menace. Though these estimates seem high but morbidity and mortality due to PPR may vary considerably from $0 \%$ $90 \%$ depending on the animal husbandry, breed, age, exposure history and virulence of PPRV strain involved [2]. The disease is more pronounced in goats as compared to sheep invariably with fatal results. The findings of present study support that PPR in goats is more severe than in sheep in Pakistan. During field investigations, some farmers and veterinarians had an opinion that PPR outbreaks peaks every three years. Though other morbilliviruses like human measles and rinderpest viruses also exhibit such cyclic pattern due to a fresh pool of susceptible host population, this assumption for PPRV requires further investigation.

Pakistan has a mixed population of 80.28 millions of small ruminants (goats 53.78 millions and sheep 26.48 millions) [25] with a varying population density in different parts of the country. Large susceptible population has the potential for the persistence and spread of morbilliviruses to other animals [26]. Possibly, densely populated pockets of small ruminants are serving as the reservoirs of PPRV and are an important in maintenance and 
transmission of infection.

The disease map of these outbreaks suggests that PPR is widespread in small ruminants of Pakistan (Figure 1). Almost all of these outbreaks can be attributed to either common grazing with local or nomadic flocks or the introduction of a new animal or animals that were sent to some livestock market for sale, but returned unsold. It can be postulated that introduction of new animals into the flock from weekly livestock markets started a new outbreak. The disease, then, spread during communal grazing with local animals. Introduction of new animals from livestock market resulted in PPR outbreaks in sheep in Saudi Arabia [10] [26]. Numerous outbreaks have occurred when farmers added newly purchased potentially incubating animals to their flocks [10]. Most outbreaks occurred during winter season. This coincided with religious festival of Eid ul Azha when there is a lot of stock movement for the purpose of sacrifice. There is also stock movement before the onset of winters in the country. The production systems for the small ruminants in Pakistan are extensive viz. nomadic (44\%), transhumant (38\%) and sedentary/household (18\%) [27]. The movement of livestock takes place in October and November every year from rain fed areas to low land pastures in canal irrigated areas. This occurs at the time of cotton picking and sugar cane harvesting in south Punjab and upper and middle Sindh. Furthermore, there is a lot of cross border nomadic movement of small ruminants from Afghanistan. The Afghan nomads visit different areas especially riverbanks and irrigated areas of KPK, Punjab and Sindh provinces of Pakistan in September and October every year and stay until April. During wheat harvesting, they return to Afghanistan following same routes. Reportedly, PPR is endemic in Afghanistan [28]. Some parts of country especially those in Baluchistan (having high small ruminant population) are not well represented in this study due to poor reporting, it is quite reasonable to assume that PPR may be equally prevalent there.

The overall findings from the outbreak investigations are suggestive that close contact between the infected and susceptible animals is the main mode of virus transmission. These findings are in consistence with those reported earlier [10] [22]. It was also found that isolation and quarantine of early cases during an outbreak proved effective in preventing the further spread of disease.

The disease reporting and surveillance networks are not very efficient in Pakistan. It is quite possible that some or many of the PPR outbreaks were not reported. It was observed that more PPR outbreaks were reported in 2006 and 2007 than 2005 indicating an increase in the incidence of PPR. It may also be suggestive of an increased awareness along with improvement in the disease-reporting network in Pakistan. Nevertheless, these findings suggest that such networks are very important for early detection and ultimately control of PPR in small ruminants.

The findings of this study suggest that PPR has established as an endemic infection in Pakistan. Animal movement and lack of quarantine are the main sources of PPR outbreaks in susceptible population. This calls for a comprehensive strategy to improve the disease reporting and surveillance activities, farmers' awareness regarding quarantine and other measures for PPR and other TADs to reduce the economic losses and further studies to understand epidemiology of PPR in small ruminants in Pakistan.

\section{Acknowledgements}

We are thankful to FAO project (GCP/PAK/127/USA) Progressive control of Peste des Petits Ruminants in Pakistan for providing financial assistance for this study.

\section{References}

[1] Furley, C.W., Taylor W.P. and Obi. T.U. (1987) An Outbreak of Peste des Petits Ruminants in a Zoological Collection. Veterinary Record, 7.

[2] Diallo, A. (2006) Control of Peste des Petits Ruminants and Poverty Alleviation. Journal of Veterinary Medicine, 53, 11-13. http://dx.doi.org/10.1111/j.1439-0450.2006.01012.x

[3] Baldlock, C., Forman, T., Geering, B. and Taylor, W.P. (1999) Report of the FAO-Japan Cooperative Project “Collection of Information on Animal Production and Health” FAO, Infectious Diseases-EMPRES Group: Rome, Italy.

[4] Perry, B.D., Randolph, T.F., McDermott, J.J., Sones, K.R. and Thornton, P.K. (2002) Investing in Animal Health Research to Alleviate Poverty. ILRI (International Livestock Research Institute), Nairobi, Kenya.

[5] Odo, B.I. (2003) Comparative Study of Some Prevalent Diseases of Ecotype Goats Reared in Southeastern Nigeria. Small Ruminant Research, 50, 203-207. http://dx.doi.org/10.1016/S0921-4488(03)00101-9

[6] Gibbs, E.P.J., Taylor, W.P., Lawman, M.J.P. and Bryant, J. (1979) Classification of Peste des Petits Ruminants Virus 
as the Fourth Member of the Genus Morbillivirus. Intervirology, 11, 268-274. http://dx.doi.org/10.1159/000149044

[7] Gargadennec, L. and Lalanne. A. (1942) La Peste des Petits Ruminants. Bull. Serv. Zoo. A. O. F., 5, 15-21.

[8] Shaila, M.S., Shamaki, D., Forsyth, M.A., Diallo, A., Goatley, L., Kitching, R.P. and Barrett, T. (1996) Geographic Distribution and Epidemiology of Peste des Petits Ruminants Viruses. Virus Research, 43, 149-153. http://dx.doi.org/10.1016/0168-1702(96)01312-3

[9] Ozkul, A., Akca, Y., Alkan, F., Barrett, T., Karaoglu, T., Daglap, S.B., Anderson, J., Yesilbag, K., Cokcaliskan, C., Genacy, A. and Burgu, I. (2002) Prevalence, Distribution, and Host Range of Peste des Petits Ruminants Virus, Turkey. Emerging Infectious Diseases Journal, 8, 709-712. http://dx.doi.org/10.3201/eid0807.010471

[10] Taylor, W.P. and Barrett, T. (2007) Rinderpest and Peste des Petits Ruminants. In: Aitken, I.D., Ed., Diseases of Sheep, Blackwell Publishing, Oxford, 450-469. http://dx.doi.org/10.1002/9780470753316.ch61

[11] Wang, Z., Bao, J., Wu, X., Liu, Y., Li, L., Liu, C., Suo, L., Xie, Z., Zhao, W., Zhang, W., Yang, N., Li, J., Wang, S. and Wang, J. (2009) Peste des Petitis Ruminants Virus in Tibet, China. Emerging Infectious Diseases Journal, 15, 299-301. http://dx.doi.org/10.3201/eid1502.080817

[12] FAO. (2009) PPR in Morocco, EMPRESS., Editor.

[13] Athar, M., Muhammad, G., F., A., Shakoor, A., Maqbool, A. and Chaudhry, N.I. (1995) An Outbreak of Peste des Petits Ruminants-Like Disease Among Goats in Punjab (Pakistan). Pakistan Veterinary Journal, 15, 140-143.

[14] Abubakar, M., Ali, Q. and Khan, H. (2008) Prevalence and Mortality Rate of Peste des Petitis Ruminant (PPR): Possible Association with Abortion in Goat. Tropical Animal Health and Production, 40, 317-321. http://dx.doi.org/10.1007/s11250-007-9105-2

[15] Khan, H.A., Siddique, M., Abubakar, M., Arshad, M.J. and Hussain, M. (2008) Prevalence and Distribution of Peste des Petits Ruminants Virus Infection in Small Ruminants. Small Ruminant Research, 79, 152-157.

[16] Zahur, A.B., Irshad, H., Hussain, M., Ullah, A., Jahangir, M., Khan, M.Q. and Farooq, M.S. (2008) The Epidemiology of Peste des Petits Ruminants In Pakistan. Rev. sci. tech. Off. int. Epiz., 27, 877-884.

[17] Thrusfield, M. (2005) Veterinary Epidemiology. 3rd Edition, Blackwell Publishing, Oxford.

[18] Kirkwood, B.R. and Sterne, J.A.C. (2003) Medical Statistics. 2nd Edition, Blackwell Sciences, London.

[19] Anderson, J. and McKay, J.A. (1994) The Detection of Antibodies against Peste des Petits Ruminants Virus in Cattle, Sheep and Goats and the Possible Implications to Rinderpest Control Programmes. Epidemiology \& Infection, 112, 225-231. http://dx.doi.org/10.1017/S0950268800057599

[20] IAEA and FAO, ELISA Data Interchange. Vienna, Austria.

[21] Libeau, G., Diallo, A., Colas, F. and Guerre, L. (1994) Rapid Differential Diagnosis of Rinderpest And Peste des Petits Ruminants Using an Immunocapture ELISA. Veterinary Record, 134, 300-304. http://dx.doi.org/10.1136/vr.134.12.300

[22] Taylor, W. (1984) The Distribution and Epidemiology of Peste des Petits Ruminants. Preventive Veterinary Medicine, 2, 157-166. http://dx.doi.org/10.1016/0167-5877(84)90059-X

[23] Chowdhury, S.A. and Mutalib, A. (2003) Goat Production in Bangladesh—Present Status and Future Programme. International Seminar on Goat Production. Islamabad, Paksitan.

[24] Roeder, P.L. and Obi, T.U. (1999) Recognizing Peste des Petites Ruminants: A Field Manual. FAO Animal Health Manual, 5.

[25] Government of Pakistan (2006) Livestock Census, A.C. Organization, Editor. 2006: Lahore.

[26] Anderson, E.C. (1995) Morbillivirus Infections in Wildlife (in Relation to Their Population Biology and Disease Control in Domestic Animals. Veterinary Microbiology, 44, 319-332. http://dx.doi.org/10.1016/0378-1135(95)00026-7

[27] Ishaque, S.M. (1993) Sheep Management System, in Sheep Production in Pakistan. In: Mackintosh, J.B., Ed., Pakistan Agricultural Research Council: Islamabad, Pakistan.

[28] Majok, A.A. (2001) Animal Health Component, in Annual Report. Islamabad, Pakistan. 
Scientific Research Publishing (SCIRP) is one of the largest Open Access journal publishers. It is currently publishing more than 200 open access, online, peer-reviewed journals covering a wide range of academic disciplines. SCIRP serves the worldwide academic communities and contributes to the progress and application of science with its publication.

Other selected journals from SCIRP are listed as below. Submit your manuscript to us via either submit@scirp.org or Online Submission Portal.
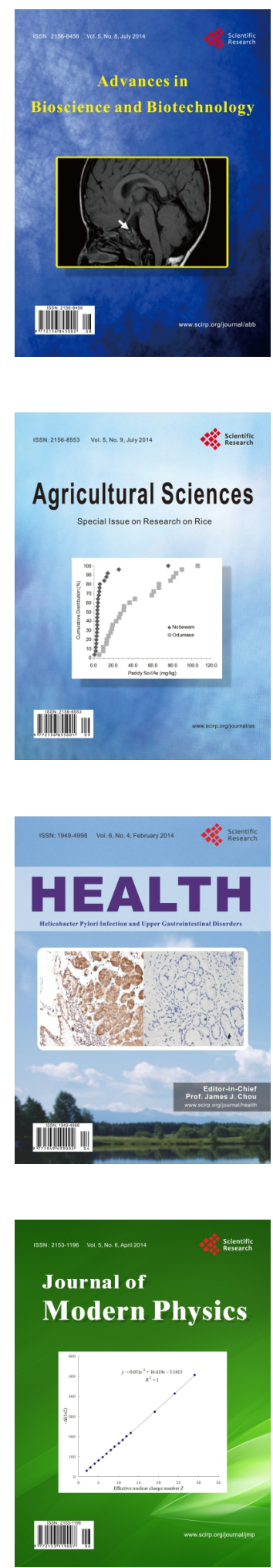
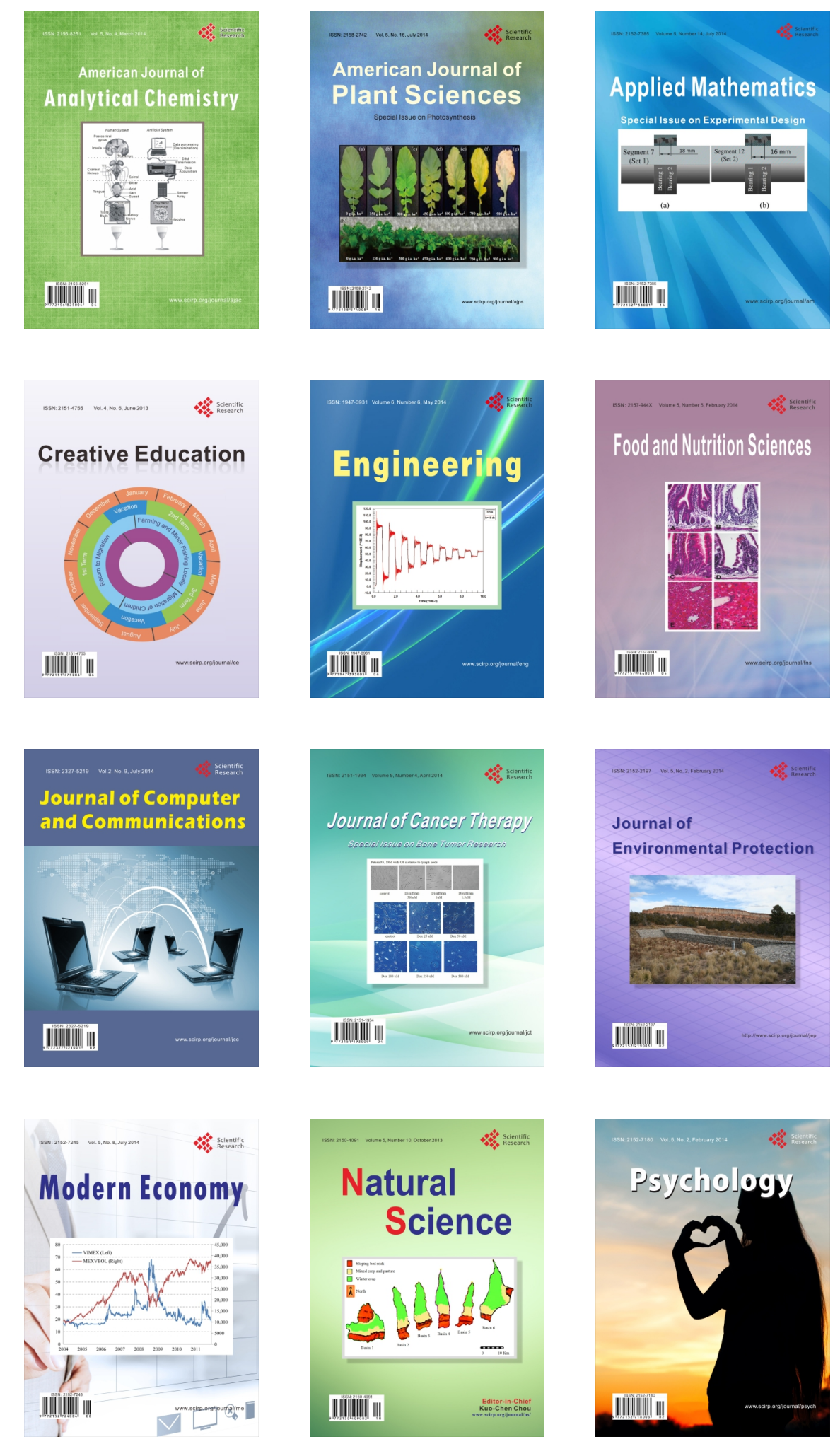